\title{
EVALUATION OF THE ANTITYROSINASE AND ANTIOXIDANT POTENTIAL OF ZINC OXIDE NANOPARTICLES SYNTHESIZED FROM THE BROWN SEAWEED-TURBINARIA CONOIDES
}

\author{
KHOUSHIKA RAAJSHREE R., BRINDHA DURAIRAJ* \\ Department of Biochemistry, PSG College of Arts and Science, Coimbatore, Tamil Nadu, India \\ Email: rangaswamyteertha@gmail.com
}

Received: 20 Jun 2017, Revised and Accepted: 22 Aug 2017

\section{ABSTRACT}

Objective: The present study was designed to evaluate the antioxidant and antityrosinase properties of zinc oxide nanoparticles (ZnO-NPs) synthesized from brown seaweed Turbinaria conoides.

Methods: Zinc Oxide Nanoparticles were synthesized from the hydroethanolic extract of Turbinaria conoides. Ultraviolet-Visible Spectrophotometric analysis was performed to confirm the formation of ZnO-NPs. Size, morphology and elemental composition of ZnO-NPs were analysed using SEM-EDAX. The antioxidant activity of the synthesized zinc oxide nanoparticles was investigated by total antioxidant capacity (phosphomolybdenum method), reducing power assay and ferric reducing antioxidant power assay (FRAP). Anti tyrosinase activity was assessed to validate the skin whitening ability of the ZnO-NPs.

Results: The antioxidant activity of ZnO-NPs synthesized from hydroethanolic extract of Turbinaria conoides was maximum when compared with that of the hydroethanolic algal extract. The antityrosinase activity of ZnO-NPs was found to be maximum with $75 \%$ tyrosinase inhibition when compared to hydroethanolic algal extract which had $56 \%$ inhibition at $250 \mu \mathrm{g} / \mathrm{ml}$ concentration.

Conclusion: Overall our study provides a firm evidence to support that antityrosinase and antioxidant activities are exhibited by ZnO-NPs synthesized from hydroethanolic extract of Turbinaria conoides and it might be used as an antioxidant and as a source of skin whitening agent in cosmetics.

Keywords: Antityrosinase activity, SEM-EDAX, FRAP, Turbinaria conoides

(C) 2017 The Authors. Published by Innovare Academic Sciences Pvt Ltd. This is an open access article under the CC BY license (http://creativecommons.org/licenses/by/4.0/] DOI: http://dx.doi.org/10.22159/ijap.2017v9i5.20847

\section{INTRODUCTION}

The skin is an important barrier which protects our body from the damage due to direct contact with the outside environment. UV irradiation is a harmful environmental factor that damages the skin and is involved in the formation and delivery of melanin within melanosomes [1]. Melanin is the major pigment for color of the human. It is secreted by melanocyte cells in the basal layer of the epidermis [2]. The melanin may be overproduced with chronic sun exposure resulting in malignant melanoma or other hyperpigmentation diseases [3]. In recent years, a number of depigmenting agents have been developed for undesirable skin discoloration [4].

Oxidative stress due to UV radiation results in the depletion of antioxidant defense system and was correlated with melanogenesis [5]. To prevent hypermelanosis antioxidant defense system must be promoted. Medicinal plant with antioxidant properties are used in skin whitening products as ultraviolet radiation dependent stress is believed to aggravate hyperpigmentation, which is one of the most common facial disorders [6]. Tyrosinase is a copper containing monooxygenase and is used in the melanin biosynthetic pathway. Tyrosinase catalyses the oxidation of L-tyrosine to 3,4 Dihydroxyphenyl L-alanine (L-DOPA), followed by the oxidation of L-DOPA to dopaquinone derivatives which yields melanin. Tyrosinase inhibitors are increasingly used in the cosmetic industry due to their skin whitening effect and for the treatment of hyperpigmentation by UV irradiation [7].

The synthetic substance in cosmetic products for long term use can cause side effects, including carcinogenesis, atrophy and ochronosis [8]. Cosmetics from natural sources are considered safer, better and eco friendly [9]. Herbal, marine and pharmaceutical agents are traditionally used to treat hyperpigmentation [10]. The rapid development of nanotechnology has resulted in an increasing number of nanomaterial-based consumer products and industries. Because of their unique physical properties, nanomaterials have dramatically transformed the function and application of commercial products, including cosmetics [11]. Recently, zinc oxide nanoparticles (ZnO-NPs) gained popularity as inorganic physical sunscreens because they can reflect and scatter UVA and UVB radiations while preventing skin irritation and disruption of the endocrine system typically induced by chemical UV filters [12].

Seaweeds are macrophytic marine algae that produce a great variety of secondary metabolites having broad spectrum of biological activities. To investigate the potential of ZnO-NP's in pharmaceutical and cosmetic products, this study was formulated to evaluate the antioxidant and antityrosinase activities of ZnO-NP's synthesized using Turbinaria conoides.

\section{MATERIALS AND METHODS}

\section{Chemicals and reagents}

The chemicals and reagents used in the study were of the highest purity and analytical reagents grade. The chemicals were purchased from SD Fine Chem., Himedia and Sigma, India.

\section{Collection and preparation of seaweed}

The brown seaweed, Turbinaria conoides (J. Agardh, Kutzing, 1860), was collected from Mandapam coastal region, Gulf of Mannar, Southeast coast of India. The algal samples were washed thoroughly with running tap water followed by distilled water to remove adhering salts and associated biota. The washed samples were dried under shade at room temperature for a week. The dried materials were ground to fine powder using mixer grinder and stored in airtight container for further analysis.

\section{Preparation of algal extract}

The pure algal extract (PAE) was prepared by adding $10 \mathrm{~g}$ of algal powder into $100 \mathrm{ml}$ of hydro ethanol (50\% ethanol) and kept in rotatory shaker for $24 \mathrm{~h}$. Filtered, collected the solvent and was used for further analysis.

Green Synthesis of zinc oxide nanoparticles (ZnO-NPs) from hydroethanolic algal extract

$20 \mathrm{ml}$ of the hydroethanolic algal extract was heated at $50^{\circ} \mathrm{C}$ for $10 \mathrm{~min}$ and $50 \mathrm{ml}$ of $91 \mathrm{mmol}$ of zinc acetate solution $1 \mathrm{~g}$ of zinc acetate was 
dissolved in $50 \mathrm{ml}$ of distilled water) was added dropwise. This was then placed in a magnetic stirrer for $2 \mathrm{~h}$. Then the precipitate was collected by centrifugation at $16000 \mathrm{rpm}$ for $10 \mathrm{~min}$ at $4^{\circ} \mathrm{C}$. The pale white precipitate was then taken out and washed over and over again with distilled water followed by ethanol to get free of the impurities. The $\mathrm{ZnO}$-NP was obtained after drying at $60^{\circ} \mathrm{C}$ in oven overnight and the sample was stored for further studies.

\section{Characterisation of zinc oxide nanoparticles}

The obtained $\mathrm{ZnO}$-NPs were measured for its maximum absorbance using UV-Vis spectrophotometry. The optical property of zinc oxide nanoparticles was determined via ultraviolet and visible absorption spectroscopy in the range of 280-420 nm. External morphology i.e. shape of the nanoparticles were characterized by Scanning Electron Microscope (SEM). Elemental analysis was obtained from energy dispersive X-ray diffraction (EDX), which was attached with SEM.

\section{Antioxidant assay}

The antioxidant activity of the synthesized $\mathrm{ZnO}-\mathrm{NP}$ and hydroethanolic algal extract was determined by employing the following methods.

\section{Total antioxidant capacity (TAC) by phosphomolybdenum method}

The total antioxidant capacity was evaluated by the phosphomolybdenum method according to the procedure described by Prieto et al. [13]. The method is based on the reduction of Mo (VI) to Mo (V) by the sample and subsequent formation of green phosphate/Mo (V) complex at acid pH. $0.3 \mathrm{ml}$ of the sample $(50-250 \mu \mathrm{g} / \mathrm{ml})$ was combined with $3 \mathrm{ml}$ of reagent solution $(0.6 \mathrm{M}$ sulfuric acid, $28 \mathrm{mmol}$ sodium phosphate and $4 \mathrm{mmol}$ ammonium molybdate). The absorbance of the reaction was measured at $695 \mathrm{~nm}$ using a spectrophotometer. Ethanol ( $0.3 \mathrm{ml}$ ) was used as the blank. The calibration curve was prepared by using ascorbic acid at different concentration (50 to $250 \mu \mathrm{g} / \mathrm{ml})$.

\section{Reducing power assay}

Reducing power was determined according to the method of Oyaizu [14]. The sample $(2.5 \mathrm{ml})$ was mixed with $2.5 \mathrm{ml}$ of $200 \mathrm{mmol}$ sodium phosphate buffer ( $\mathrm{pH} 6.6$ ) and $2.5 \mathrm{ml}$ of $1 \%$ potassium ferricyanide and the mixture was incubated at $50^{\circ} \mathrm{c}$ for $20 \mathrm{~min}$. Then $2.5 \mathrm{ml}$ of $10 \%$ trichloroacetic acid was added, the mixture was centrifuged at $3000 \mathrm{X}$ $\mathrm{g}$ for $10 \mathrm{~min}$. The upper layer $(2.5 \mathrm{ml})$ was mixed with $2.5 \mathrm{ml}$ of deionized water and $0.5 \mathrm{ml}$ of $0.1 \%$ ferric chloride. Finally, the absorbance was measured at $700 \mathrm{~nm}$ against a blank.

\section{Ferric reducing/antioxidant power assay}

The ferric reducing/antioxidant power (FRAP) assay was carried out according to the method described by Okonogi [15]. This assay measures the reducing properties of antioxidants based on the reduction of ferric ion. Therefore, ferrous sulfate (FeSO4) was used for calibration. A freshly prepared FRAP solution contained $50 \mathrm{ml}$ of $0.3 \mathrm{M}$ acetate buffer (pH 3.6) was added to $5 \mathrm{ml}$ of $10 \mathrm{mmol} \mathrm{TPTZ} \mathrm{solution} \mathrm{in} 40 \mathrm{mmol} \mathrm{HCl}$ (previously prepared) and $5 \mathrm{ml}$ of $20 \mathrm{mmol}$ ferric chloride. After mixing $2.85 \mathrm{ml}$ of FRAP solution with $20 \mu \mathrm{L}$ of each sample, the ferric reducing ability was measured at the end of $30 \mathrm{~min}$ at an absorbance of $590 \mathrm{~nm}$.

\section{Antityrosinase activity}

\section{Extraction of tyrosinase from potato}

One hundred grams of peeled potato was homogenized in a blender with $100 \mathrm{ml}$ of sodium fluoride. This was homogenized for about one minute at high speed. The homogenate was filtered through several layers of cheesecloth. An equal volume of saturated ammonium sulphate was added to the filtrate. A flocculent white precipitate was formed. The ammonium sulphate treated homogenate is divided into chilled centrifuge tubes and centrifuged at1, $500 \mathrm{x} \mathrm{g}$ for $5 \mathrm{~min}$ at $4{ }^{\circ} \mathrm{C}$. Supernatant was carefully discarded and the pellet was collected. All of the pellets were combined into $60 \mathrm{ml}$ of citrate buffer, $\mathrm{pH}$ 4.8. Again the solution is divided into centrifuge tubes and centrifuged at $300 \mathrm{xg}$ for 5 min at $4{ }^{\circ} \mathrm{C}$. The supernatant (enzyme) was collected and saved for further use [16].

\section{Determination of tyrosinase inhibitor activity}

The mixture was prepared by adding $10 \mu \mathrm{l}$ tyrosinase $20 \mu \mathrm{l} 1.5 \mathrm{mmol}$ L-tyrosine, $10 \mu \mathrm{l} 1.5 \mathrm{mmol}$ sample and $110 \mu \mathrm{l}$ of $0.1 \mathrm{M}$ sodium phosphate buffer (pH 6.5). The resulting mixture $(150 \mu \mathrm{l})$ was incubated for $10 \mathrm{~min}$ at $37{ }^{\circ} \mathrm{C}$ and absorption at $490 \mathrm{~nm}$ was measured. Arbutin was used as the reference Tyrosinase inhibitor. The test was performed in triplicate. The percent inhibition of tyrosinase activity was calculated as given in the formula [17]:

$$
\operatorname{Inhibition}(\%)=\frac{A b s(\text { control })-A b s(\text { extract })}{A b s(\text { control })} \times 100
$$

\section{Statistical analysis}

The results obtained were reported as mean \pm standard deviation.

\section{RESULTS}

\section{Biosynthesis of ZnO-NPs using brown seaweed}

ZnO-NPs were synthesized from hydroethanolic extract of Turbinaria conoides by green synthesis method, which is more reliable and less toxic when compared with other methods. The formation of pale white colour within $3 \mathrm{~h}$ of preparation indicated the synthesis of $\mathrm{ZnO}$-NPs.

\section{UV-visible spectral analysis}

The optical absorption spectra of $\mathrm{ZnO}$-NPs were recorded using UV/VIS 3000+Double Beam UV Visible Ratio-Recording Scanning Spectrophotometer from Lab India (SKU: 174-0020) with dimensions of $(\mathrm{W} \times \mathrm{D} \times \mathrm{H}) /$ Weight $=540 \times 440 \times 390 \mathrm{~mm} / 36 \mathrm{~kg}$. Spectral bandwidth of Spectrophotometer is $0.5,1,2,5 \mathrm{~nm}$ and wavelength is in the range of 190 to $1100 \mathrm{~nm}$. Fig. 1 shows the UVVis absorption spectrum of ZnO-NPs. The absorption spectrum was recorded for the sample in the range of $280-420 \mathrm{~nm}$. The spectrum showed the absorbance peak at $360 \mathrm{~nm}$ corresponding to the characteristic band of $\mathrm{ZnO}-\mathrm{NPs}$.

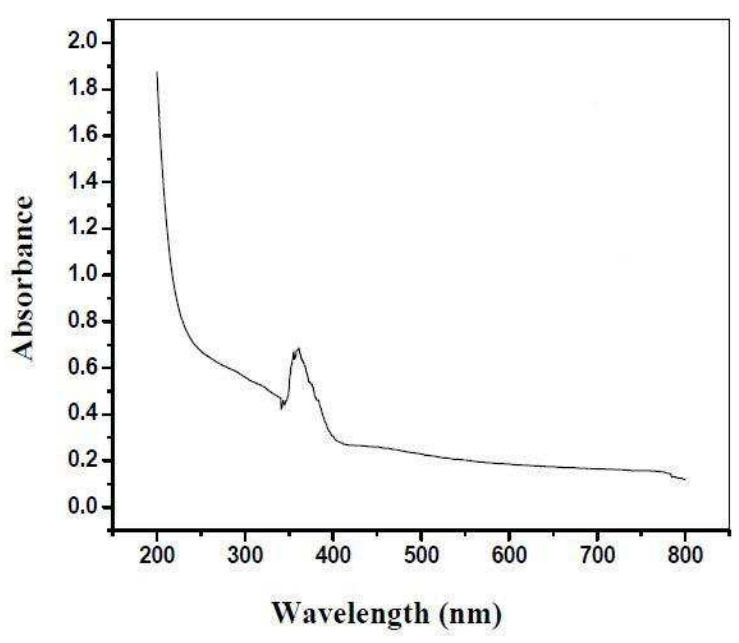

Fig. 1: UV-visible spectrum of synthesized ZnO-NPs

\section{Scanning electron microscopy (SEM) analysis}

The morphology of the synthesized nanoparticles was examined using scanning electron microscopy. Fig. 2(a) and fig. 2(b) show the surface morphology of the zinc oxide nanoparticles under different magnifications. The SEM image showed that most of the nanoparticles are spherical in shape formed within diameter range of $80-130 \mathrm{~nm}$.

\section{Energy dispersive X-Ray diffractive (EDX) analysis}

The Energy Dispersive X-ray Diffractive (EDX) study was carried out for the synthesized $\mathrm{ZnO}$-NPs to elucidate the elemental composition. EDX confirms the presence of zinc and oxygen signals of ZnO-NPs as depicted in fig. 3 . The results revealed the peaks that correspond to the optical absorption of the produced nanoparticle. The elemental analysis of the nanoparticle yielded $77.32 \%$ of zinc and $22.68 \%$ of oxygen which proves that the produced nanoparticle is in its highest purified form. 

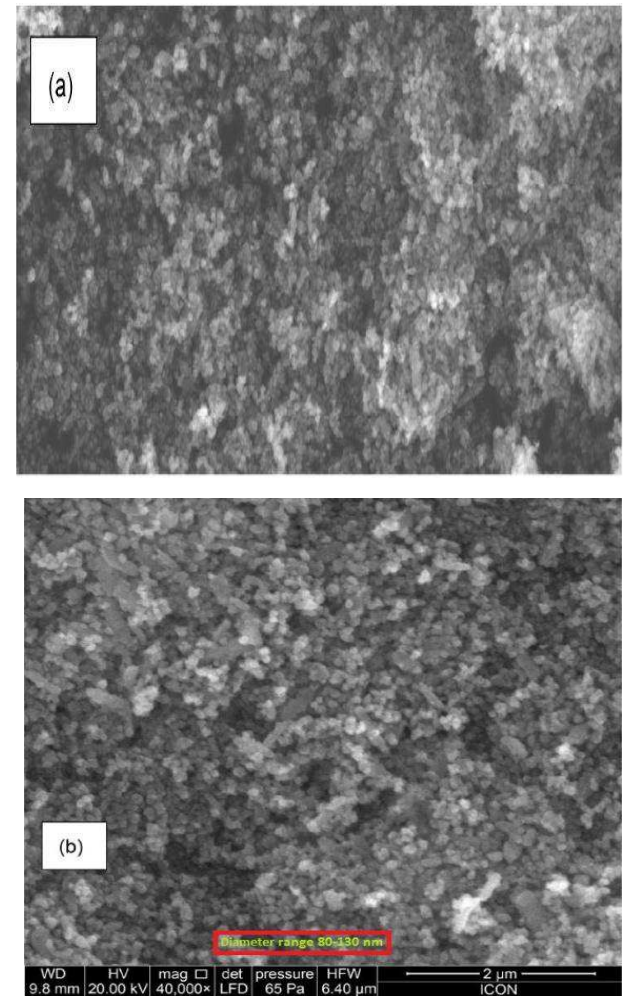

Fig. 2: [a] and [b]: SEM image of the synthesized ZnO-NPs

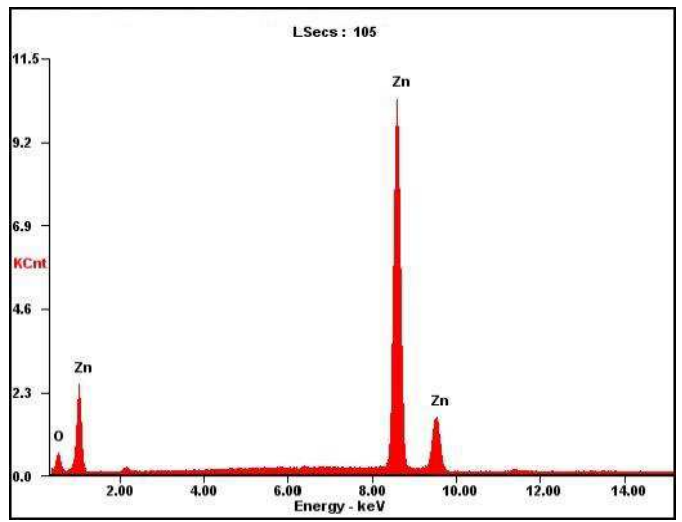

Fig. 3: EDX spectrum of synthesized ZnO-NPs

\section{Antioxidant assay}

\section{Total antioxidant capacity (TAC) by phosphomolybdenum method}

The total antioxidant capacity was evaluated by the phosphomolybdate method. The basic principle to assess the antioxidant capacity through phosphomolybdenum assay which includes the reduction of Mo (VI) to Mo (V) by the sample possessing antioxidant properties. The total antioxidant capacity of ZnO-NPs was found to be $70 \%$ when compared with the crude algal extract at a concentration of $250 \mu \mathrm{g} / \mathrm{ml}$ and for the standard ascorbate it was found to be 76\% (fig. 4).

\section{Reducing power assay}

The transformation of $\mathrm{Fe}^{3+}$ /ferricyanide complex to $\mathrm{Fe}^{2+}$ in the presence of various concentrations of ZnO-NPs $(50-250 \mu \mathrm{g} / \mathrm{ml})$ and standard was assessed and depicted in fig. 5. Maximum reducing power was exhibited by $\mathrm{ZnO}$-NPs when compared to the crude algal extract. Absorbance of $\mathrm{ZnO}-\mathrm{NP}$ and standard were found to be 0.69 and 0.81 respectively at $250 \mu \mathrm{g} / \mathrm{ml}$ concentration. Increased absorbance of reaction mixture indicated increased reducing power.
It is evident that both the sample and standard exhibited maximum reducing power only at higher concentration. The presence of reductants in the synthesized $\mathrm{ZnO}$-NPs causes the reduction of $\mathrm{Fe}$ ${ }^{3+} /$ Ferricyanide complex to the ferrous form.

\section{Ferric reducing antioxidant power (FRAP)}

The ferric reducing capacity of the compound may serve as a significant role in its potential antioxidant capacity. This depends upon the reduction of ferric tripyridyltriazine (Fe (III)-TPTZ) complex to the ferrous tripyridyltriazine (Fe (II)-TPTZ) by a reductant at low $\mathrm{pH}$. In the presence of TPTZ complex, the reduction is accompanied by the formation of a colored complex with Fe (II). The synthesized ZnO-NP showed increased FRAP activity (73\%) when compared with that of crude algal extract while the standard ascorbate was found to be $77 \%$ (fig. 6).

\section{Determination of antityrosinase activity}

The antityrosinase activity of the synthesized ZnO-NPs was represented in fig. 7. The synthesized ZnO-NP exhibited tyrosinase inhibitory activity in a concentration dependent manner (50$250 \mu \mathrm{g} / \mathrm{ml}$ ). The nanoparticle sample revealed high inhibition percentage $(75 \%)$ of tyrosinase activity when compared to the crude algal extract and standard arbutin which was found to have $56 \%$ and $73 \%$ tyrosinase inhibition at a concentration of $250 \mu \mathrm{g} / \mathrm{ml}$ respectively.

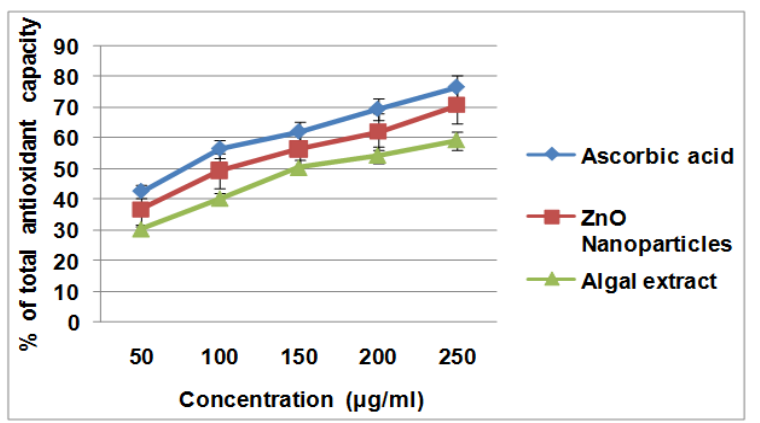

Fig. 4: Total antioxidant capacity of ascorbic acid, ZnO-NP and algal extract, (Values are expressed as mean \pm SD)

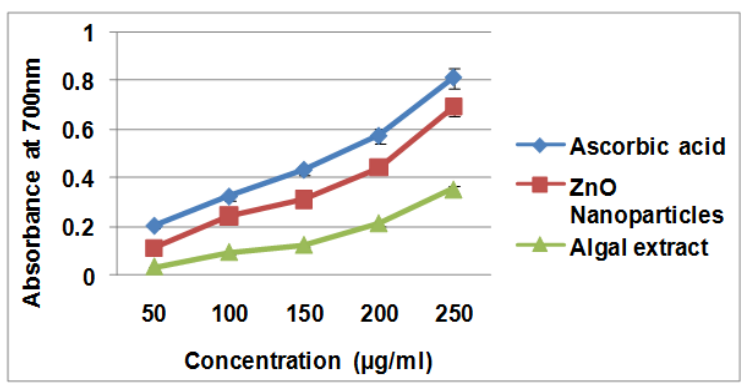

Fig. 5: Reducing power assay for ascorbic acid, $\mathrm{ZnO}$-NP and algal extract, (Values are expressed as mean $\pm \mathrm{SD}$ )

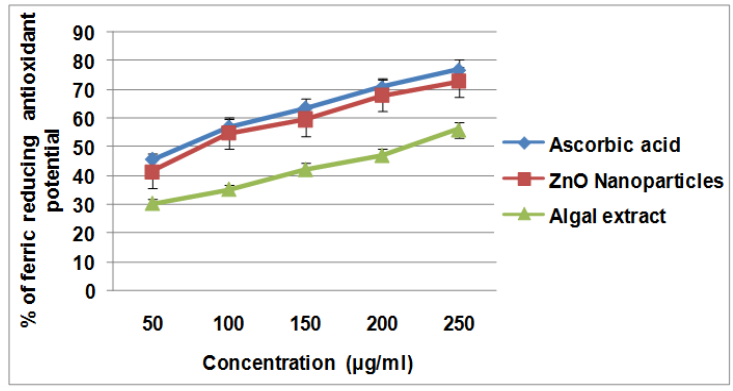

Fig. 6: FRAP Assay for ascorbic acid, ZnO-NP and algal extract, (Values are expressed as mean $\pm \mathrm{SD}$ ) 


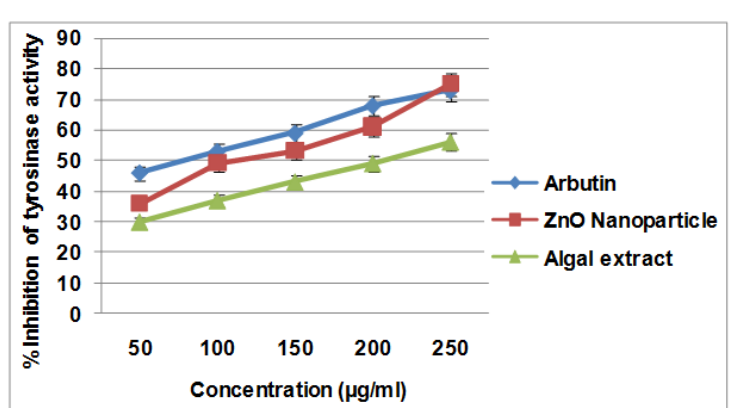

Fig. 7: Antityrosinase activity of ascorbic acid, ZnO-NP and algal extract, (Values are expressed as mean $\pm \mathrm{SD}$ )

\section{DISCUSSION}

In recent years there is an increased demand for natural substances which can be used for depigmenting, anti wrinkle, and other cosmeceutical purposes [18]. Tyrosinase is a copper-containing enzyme that catalyzes the production of melanin from tyrosine by an oxidation reaction. Many of the depigmentation agents act at various levels of melanin production in the skin by inhibiting tyrosinase and melanogenesis. Inhibition of tyrosinase by a variety of compounds has been studied, with the result that several inhibitors are now used as cosmetic additives or as medicinal products for hyperpigmentation [19].

The role of ZnO-NPs in cosmetic industry has taken a big leap in this century. Green synthesized nanoparticles with an inhibitory effect on melanin formation and elastase activity may be good choices for cosmetic purposes because of their relatively low incidence of side effects [20]. Biosynthesized ZnO-NPs from Turbinaria conoides by green approach is confirmed visually and via UV-Vis spectrophotometer, indicating the synthesis of $\mathrm{ZnO}-\mathrm{NPs}$ is successful. Tyrosinase (EC 1.14.18.1) is the rate-limiting enzyme involved in melanin synthesis [21]. The synthesized nanoparticle shows high percentage inhibition of tyrosinase activity.

The present study is in par with the work done by Basavegowda $e t$ al. [22] who reported that the palladium nanoparticles exhibited potent antityrosinase and antioxidant activities. Salleh et al., [23] also reported that the stem of Piper officinarum exhibited both antityrosinase and antioxidant activities. Silver nanoparticles synthesized from Glycosmis mauritiana was found to show increased antityrosinase and antioxidant activities [24].

The basic principle to assess the antioxidant capacity through phosphomolybdenum assay includes the reduction of Mo (VI) to Mo (V) by the $\mathrm{ZnO}-\mathrm{NPs}$ possessing antioxidant compounds. The results of the study clearly indicate that the synthesized ZnO-NP possess antioxidant activity with respect to mechanisms of both free radical scavenging and reducing activities. In reduction power assay, it is observed that as concentration of sample increases, the absorbance also increases. Higher absorbance for the reaction mixture indicates greater reducing power [25]. The ferric reducing antioxidant potential (FRAP) assay is a simple and inexpensive method for the detection of total antioxidant levels [26]. FRAP activity is mainly due to their redox potential which plays an important role in adsorbing and neutralizing free radicals quenching singlet and triplet oxygen or decomposing peroxides. Higher FRAP value denotes higher antioxidant capacity because FRAP value is based on reducing ferric ion, where antioxidants are the reducing agents [27].

\section{CONCLUSION}

Our study revealed that the $\mathrm{ZnO}-\mathrm{NP}$ synthesized from hydroethanolic extract of Turbinaria conoides by green approach exerted potential antityrosinase and antioxidant activities. Therefore, the ZnO-NP's might be used as antioxidant for pharmaceutical products and skin whitening agent in cosmetics.

\section{ACKNOWLEDGMENT}

Authors wish to acknowledge the management of PSG College of Arts and Science, Tamil Nadu, India, for providing the necessary laboratory facilities.

\section{CONFLICT OF INTERESTS}

Declared none

\section{REFERENCES}

1. Braverman IM, Fonferko E. Studies in cutaneous aging: the elastic fiber network. J Invest Dermatol 1982;78:434-43.

2. Hearing VJ. Biogenesis of pigment granulesa sensitive way to regulate melanocyte function. J Dermatol Sci 2005;37:3-14.

3. Briganti S, Camera E, Picardo M. Chemical and instrumental approaches to treat hyperpigmentation. Pigment Cell Res 2003;16:101-10.

4. Sturm RA, Tesdeal RD, Box NF. Human pigmentation genes identification, structureand consequences of polymorphic variation. Gene 2001;277:49-62.

5. Hu ZM, Zhou Q, Lei TC, Ding SF, Xu SZ. Effects of hydroquinone and its glucoside derivatives on melanogenesis and antioxidation: biosafety as skin whitening agents. J Dermatol Sci 2009;55:179-84.

6. Kausar R, Akhtar N. Evaluation of depegmenting and antierythemic effects of cosmetic emulgels containing raspberry fruit extract on human cheek skin. Int J Pharm Pharm Sci 2017;9:236-8.

7. Raper HS. The anaerobic oxidase. Physiol Rev 1928;8:245-82.

8. Parvez S, Kang M, Chung HS, Cho C, Hong MC, Shin K, Bae H. Survey and mechanism of skin depigmenting and lightening agents. Phytother Res 2006;20:921-34.

9. Quishi C. Evaluate the effectiveness of the natural cosmetic product compared to chemical-based product. Int J Chem 2009;1:57-9.

10. Nerya O, Vaya J, Musa R, Izrael S, Ben-Arie R, Tamir S. Glabrene and isoliquiritigenin as tyrosinase inhibitors from licorice roots. J Agric Food Chem 2003;51:1201-7.

11. Wiesenthal A, Hunter L, Wang S, Wickliffe J, Wilkerson M. Nanoparticles: small and mighty. Int J Dermatol 2011;50:247-54.

12. Lorenz C, Tiede K, Tear S, Boxall A, Von Goetz N, Hungerbühler $\mathrm{K}$. Imaging and characterization of engineered nanoparticles in sunscreens by electron microscopy, under wet and dry conditions. Int J Occup Environ Health 2010;16:406-8.

13. Prieto P, Pineda M, Aguilar M. Spectrophotometric quantitation of antioxidant capacity through the formation of phosphomolybdenum complex: specific application to determination of vitamin E. Anal Biochem 1999;269:337-41.

14. Oyaizu M. Studies on products of browning reactions: Antioxidative activities of products of browning reactions prepared from glucoamine. Jpn J Nutr 1986;4:307-15.

15. Okonogi S, Duangrat C, Anuchpreeda S, Tachakittirungrod S, Chowwanapoonpohn S. Comparison of antioxidant capacities and cytotoxicities of certain fruit peels. Food Chem 2007;103:839-46.

16. Friedman M. Chemistry, biochemistry and dietary role of potato polyphenols. J Agric Food Chem 1997;45:1523-40.

17. Vanni A, Gastaldi D. Kinetic investigation on the double enzymic activity of the tyrosinase mushroom. Ann Chim 1990;80:35-60.

18. Kiken DA, Cohen DE. Contact dermatitis to botanical extracts. Am J Contact Dermat 2002;13:148-52.

19. Saewan N, Thakam A, Jintaisong A, Kittigowitana K. Antityrosinase and cytotoxicity activities of curcumin-metal complexes. Int J Pharm Pharm Sci 2014;6:270-3.

20. Lu PJ, Huang SC, Chen YP, Chiueh LC, Shih DYC. Analysis of titanium dioxide and zinc oxide nanoparticles in cosmetics. J Food Drug Anal 2015;23:587-94.

21. Pintus F, Span OD, Corona A, Medda R. Antityrosinase activity of Euphorbia characias extracts. Peer J 2015. Doi:10.7717/peerj.1305.

22. Basavegowda N, Mishra K, Lee YR, Kim SH. Antioxidant and anti-tyrosinase activities of palladium nanoparticles synthesized using saururus chinensis. J Clust Sci 2015;27:1-13.

23. Salleh W, Ahmad F, Yen KH. Antioxidant and anti-tyrosinase activities from Piper officinarum (Piperaceae). J Appl Pharm Sci 2014;4:87-91.

24. Govindappa M, Farheen M, Chandrappa CP, Channabasava, Ravishankar V Rai, Raghavendra VB. Mycosynthesis of silver nanoparticles using extract of endophytic fungi, penicillium species of Glycosmis mauritiana, and its antioxidant, antimicrobial, anti-inflammatory and tyrokinase inhibitory activity. Adv Natl Sci: Nanosci Nanotechnol 2016;7:1-9. 
25. Sherikar AS, Mahanthesh MC. Evaluation of aqueous and methanolic extract of leaves of epipremnum aureum for radical scavenging activity by DPPH Method, total phenolic content, reducing capacity assay and FRAP assay. J Pharmacogn Phytochem 2015;4:36-40.

26. Dennog C, Radermacher P, Barnett YA, Speit G. Antioxidant status in humans after exposure to hyperbaric oxygen. Mutat Res 1999;428:83-9.
27. Niemeyer HB, Metzler M. Differences in the antioxidant activity of plant and mammalian lignans. J Food Eng 2003;56:255-6.

\section{How to cite this article}

- Khoushika Raajshree R, Brindha Durairaj. Evaluation of the antityrosinase and antioxidant potential OF zinc oxide nanoparticles synthesized from the brown seaweed-Turbinaria conoides. Int J Appl Pharm 2017;9(5):116-120. 